\title{
Prezgodnje odpadanje listov velikega jesena je povzročila gliva Hymenoscyphus albidus, povzročiteljica jesenovega ožiga
}

\section{Nikica OGRIS $^{1 *}$, Tine HAUPTMAN ${ }^{1}$, Mojca BOGOVIČ ${ }^{2}$}

Konec avgusta in na začetku septembra 2009 smo na različnih krajih v Sloveniji zabeležili prezgodnje odpadanje listov velikega jesena (Fraxinus excelsior L.). Prezgodnje odpadanje listov je bilo intenzivnejše v dolinah z visoko relativno zračno vlažnostjo, npr. V dolini Save od Zidanega mosta do Radeč, ozka dolina sredi Gorjancev (Jesenovski jarek), stranska dolina ob reki Mirni pred izlivom v Savo in v okolici Bohinjskega jezera. Nekatera drevesa velikega jesena so bila že konec avgusta popolnoma brez listja (slika 1). Na odpadlih listih smo na pecljih opazili nekroze (slika 2). V Laboratoriju za varstvo gozdov na Gozdarskem inštitutu Slovenije smo dokazali (z izolacijo glive $\mathrm{v}$ čisto kulturo iz nekrotičnih predelov listnih pecljev), da prezgodnje odpadanje listov velikega jesena povzroča gliva Chalara fraxinea T. Kowalski. Prezgodnje odmetavanje listov velikega jesena zaradi omenjene glive so opazovali in potrdili tudi že številni drugi raziskovalci po Evropi (Kirisits in sod., 2009). Znano je, da se gliva C. fraxinea lahko iz listnih pecljev razraste $\mathrm{v}$ poganjek (Talgø in sod., 2009) in tam povzroča odmiranje skorje in prebarvanje lesa. Zaradi okužbe lesa in odmiranja skorje odmirajo celi poganjki in venijo listi. Na odpadlih okuženih listnih pecljih se bodo v naslednjem letu od maja do oktobra razvili apoteciji glive belkaste pecljevke, Hymenoscyphus albidus (Roberge ex Desm.) W. Phillips (slika 3), ki je teleomorf glive $C$. fraxinea (Kowalski in Holdenrieder, 2009). V apotecijih se razvijajo askospore, ki jih aski izmetavajo v zrak samo nekaj mm visoko, nato jih zajame veter in jih prenaša na velike razdalje.

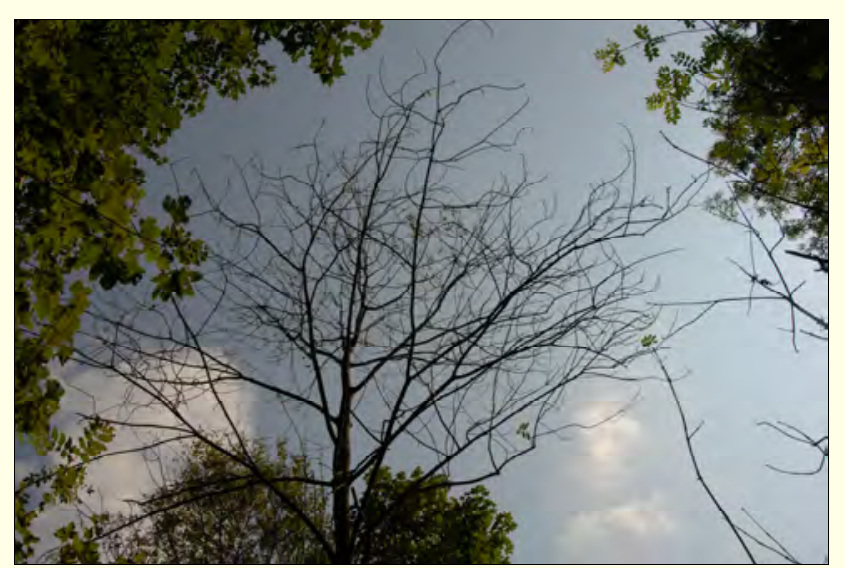

Slika 1: Nekaterim drevesom velikega jesena je vse listje odpadlo že konec avgusta.
Čeprav je velikemu jesenu prezgodaj odpadlo listje, to še ne pomeni, da je odmrlo celo drevo. Takšno drevo bo naslednjo pomlad odgnalo, vendar bo imelo predvidoma nekoliko več odmrlih poganjkov. Menimo, da bo takšno drevo velikega jesena počasi propadalo in se bo posušilo v obdobju od 10 do 15 let. Ker očitno obstajajo razlike $\mathrm{v}$ individualni odpornosti posameznih dreves velikega jesena na jesenov ožig, ne priporočamo, da se ukrepa prenaglo, saj bi s tem izgubili morebitni zelo pomemben genetski fond, t. j. odpornejša drevesa. Torej, veliki jesen opazujmo, ukrepajmo pa s sanitarno sečnjo posameznih dreves takrat, ko bo večina poganjkov in vej že odmrlih in suhih.

\section{Viri}

Kirisits T., Matlakova M., Mottinger-Koupa S., Cech T.L., Halmschlager E. 2009. The current situation of ash dieback caused by Chalara fraxinea in Austria. Proceedings of the conference of IUFRO working party 7.02.02, Eğirdir, Turkey, 11.-16. May 2009. SDU Faculty of Forestry Journal. Doğmuș Lehtijärvi T.H. Isparta, Turkey, Süleyman Demirel University: Special edition: 97-119

Kowalski T., Holdenrieder O. 2009. The teleomorph of Chalara fraxinea, the causal agent of ash dieback. Forest Pathology, doi: 10.1111/j.1439-0329.2008.00589.x

Talgø V., Sletten A., Brurberg M.B., Solheim H., Stensvand A. 2009. Chalara fraxinea isolated from diseased ash in Norway. Plant Disease, 93, 5: 548-548

${ }^{1}$ Gozdarski inštitut Slovenije, Večna pot 2, 1000 Ljubljana; 2 Zavod za gozdove Slovenije, Območna enota Brežice, Cesta bratov Milavcev 61, 8250 Brežice

*nikica.ogris@gozdis.si

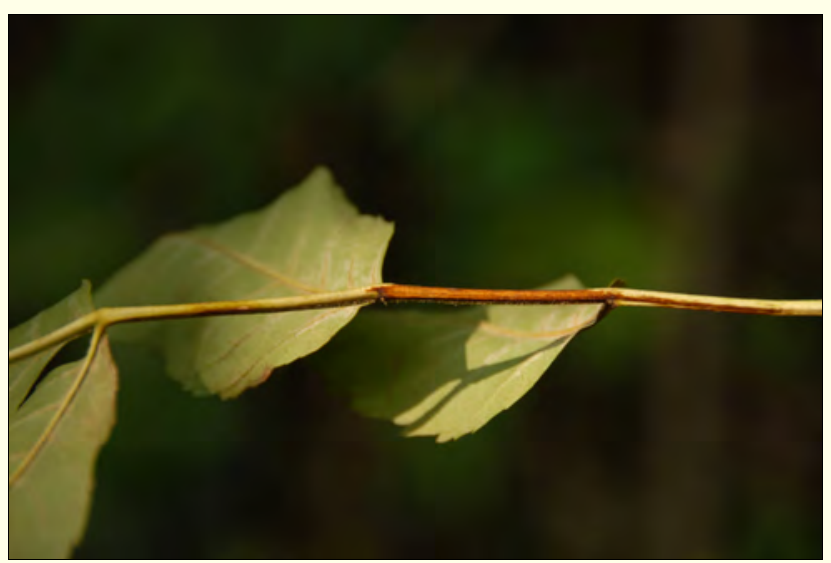

Slika 2: Na listnih pecljih so nekroze, ki jih je povzročila gliva Chalara fraxinea. To je vzrok za prezgodnje odpadanje listja velikega jesena. 


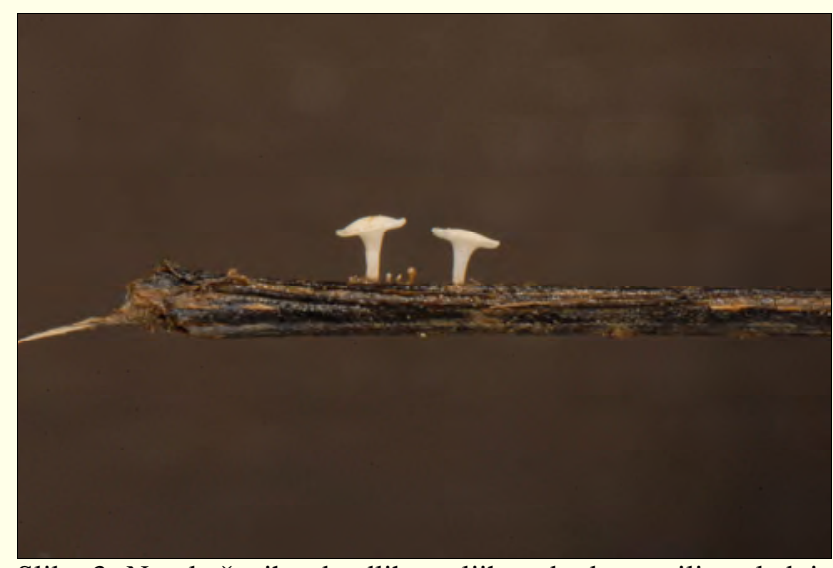

Slika 3: Na okuženih odpadlih pecljih se bodo razvili naslednje leto od pomladi do jeseni apoteciji glive Hymenoscyphus albidus, ki je teleomorf glive Chalara fraxinea.

\title{
Mraznica je poškodovala veliki jesen pri Radljah ob Dravi
}

\author{
Nikica OGRIS $^{1 *}$, Gorazd MLINŠEK ${ }^{2}$
}

Na Planini pri Radljah ob Dravi (Pahernikovi gozdovi) smo na površini 0,3 ha v sestoju velikega jesena (Fraxinus excelsior), ki je bil posajen pred 25 leti, zabeležili srednje močno poškodovanost jesena zaradi mraznice (Armillaria sp.). Mraznica je kot primarni parazit okužila korenine, koreničnik in spodnji del jesenovih debel na bogatem in vlažnem rastišču. Mraznica je samo $v$ eni rastni sezoni povzročila tudi do 50 cm dolge nekroze v skorji. Nekroza se je jezikasto širila iz korenin navzgor po deblu. Ko smo z nožem odstranili zunanji del skorje, smo v skorji in kambiju opazili podgobje bele do bež barve in pahljačastega videza (slika 1). Takšno podgobje je značilno za glivo mraznico ali štorovko. Najverjetneje gre za sivorumeno mraznico (A. mellea), ki je priložnostno zelo agresiven primarni parazit in kuži številne listavce, redkeje iglavce. Nekroza je bila v vsej dolžini sveža, t. j. odmiranje skorje in kambija se je razvilo letos. Pod nekrozo je les trohnel.

Z gotovostjo lahko predvidimo, da bodo poškodovana drevesa še naprej trohnela, slabše bodo priraščala in verjetno bodo $\mathrm{v}$ daljšem časovnem razdobju shirala in odmrla. Z veliko verjetnostjo lahko napovemo, da se bodo $\mathrm{v}$ omenjenem sestoju poškodbe zaradi mraznice širile na ostala drevesa vseh vrst in ne samo velikega jesena. Hitrost širjenja bo odvisna predvsem od zunanjih stresnih dejavnikov, ki bodo $\mathrm{v}$ prihodnosti prizadeli sestoj. Okužba se bo širila približno v koncentričnih krogih iz centrov, kjer so danes okužena drevesa.

Pri ukrepanju imamo na voljo dve možnosti. (1) Okužena drevesa posekamo. Iz sestoja odstranimo tudi panje skupaj s koreninami, v kolikor je to ekonomsko upravičeno in mogoče. Če odstranimo panje okuženih dreves, preprečimo hitro širjenje bolezni na sosednja drevesa. Mraznica se širi na dva načina: z rizomorfi in z bazidiosporami. Rizomorfi se razraščajo od okuženega panja in korenin v tleh in povzročajo okužbe zdravih korenin sosednjih dreves. Iz micelija $\mathrm{v}$ odmirajoči skorji in v kambiju prodirajo hife v les in v njem povzročajo belo trohnobo. Mraznica se $\mathrm{v}$ panjih in koreninah prehranjuje saprofitsko in dobro prehranjena lahko oblikuje veliko število rizomorfov z veliko infekcijsko sposobnostjo. Mraznica z veliko količino hrane (ki jo predstavlja panj in koreninski sistem odmrlega ali požaganega drevesa) ima bolj izražen patogeni značaj kot oslabljena mraznica, z manjšo količino razpoložljive hrane. Bazidiospore se oblikujejo na lističih trosnjakov, ki se pojavijo jeseni ob ali na koreničniku okuženega ali odmrlega drevesa. Bazidiospore lahko okužujejo drevo samo skozi rane, zato predstavlja vsaka rana, ki nastane na skorji, potencialno vstopno mesto za okužbo z mraznico. (2) Gozdnogojitveni ukrepi: v poškodovanem sestoju postopno zamenjamo okužena drevesa z bolj odpornimi drevesnimi vrstami na mraznico oziroma s takimi, ki jim rastišče najbolj ustreza. Pomembno je, da je zasaditev novih dreves redkejša in da je sestava drevesnih vrst čim bolj mešana, saj tako z večjo verjetnostjo zagotovimo manj poškodb zaradi mraznice.

${ }^{1}$ Gozdarski inštitut Slovenije, Večna pot 2, 1000 Ljubljana; ${ }^{2 Z a v o d ~ z a ~ g o z d o-~}$ ve Slovenije, Območna enota Slovenj Gradec, Vorančev trg 1, 2380 Slovenj Gradec

*nikica.ogris@gozdis.si 